\title{
Research on Airport Taxi Resource Allocation Based on Information Asymmetry
}

\author{
Yansong Zheng \\ Anhui University of Finance and Economics, Longzihu Campus, Bengbu, China \\ Email: zhengys1998@163.com
}

How to cite this paper: Zheng, Y.S. (2020) Research on Airport Taxi Resource Allocation Based on Information Asymmetry. Open Journal of Business and Management, 8, 763-769.

https://doi.org/10.4236/ojbm.2020.82046

Received: February 18, 2020

Accepted: March 16, 2020

Published: March 19, 2020

Copyright (c) 2020 by author(s) and Scientific Research Publishing Inc. This work is licensed under the Creative Commons Attribution International License (CC BY 4.0).

http://creativecommons.org/licenses/by/4.0/

(c) (i) Open Access

\begin{abstract}
Most passengers will go to the city or the surrounding destinations when they get off the plane. Taxi is one of the main means of transportation. Therefore, taxi drivers will face two options: queuing in the arrival area to wait for passengers to return to the urban area and directly returning to the urban area. In this paper, through the collection of relevant airport data and analysis and calculation methods, a fitting model is established, and a reasonable scheme is designed for the allocation of taxi resources. Based on the study and analysis of the influencing mechanism of taxi drivers' decision-making factors, and considering the changing law of airport passenger number and the income of taxi drivers, this paper puts forward the reasonable allocation scheme of airport taxi.
\end{abstract}

\section{Keywords}

Time Cost, Data Fitting, Benefit Maximization

\section{Introduction}

Most of the passengers have to go to the city's destination after getting off the plane. Taxi is one of the main means of transportation. Most of the domestic airports are separated from the reception channel. Taxi drivers who send passengers to the airport will face two choices: first, go to the arrival area and wait in line for passengers to return to the city. Taxis must wait in line at the designated "storage pool", and enter the field to pick up passengers according to the "first come, then come". The waiting time depends on the number of taxis and passengers in line, which needs to pay a certain time cost; secondly, the taxi driver will pay the no-load cost and may lose the potential passenger income by directly returning to the urban area to pick up passengers. 
The number of flights arriving in a certain period of time and the number of vehicles already in the "car storage pool" are certain information that can be observed by the driver. Usually, the decision-making of drivers is related to their personal experience judgment, such as the number of arriving flights, the number of possible passengers in a certain season and a certain period of time. If the passengers want to "take a taxi" after getting off the plane, they have to line up in the designated "loading area" and take the bus in order. Airport taxi managers are responsible for "batch and quantitative" release of taxis into the "load zone", and arrange a certain number of passengers to get on the train. In practice, there are many uncertain factors that affect the decision-making of taxi drivers, which have different relations and effects.

\section{Journals Reviewed}

At present, taxi resource allocation has become a hot topic among residents and media. On the one hand, most of the residents report that taxi prices are too expensive and it is difficult to take a taxi; on the other hand, the problem of taxi buyout operation leads to a high labor intensity of taxi drivers. Hao Bing et al. (2018) [1] used the analytic hierarchy process to collect the travel time, travel distance and cost of some passengers, analyzed the supply and demand of passengers and taxis, and believed that in order to alleviate the contradiction between the supply and demand of axis and passengers, the reception rate of taxi drivers should be improved. Yi Changzhong (2018) [2] analyzed the problem of taxi difficulty from the perspective of taxi drivers to maximize profits, established multiple logit models for taxi resource allocation, and believed that the probability of passengers taking a taxi and the distance between the taxi and passengers were negatively correlated. With the advent of the "Internet plus" era, the problem of taxi resource allocation has been solved. Therefore, the growth model of block growth has been established by Ma Saisai (2018) [3] and so on. The proportion of taxis traveling by residents is predicted, which provides scientific data support for taxi resource allocation. Wang Meina et al. (2017) [4] collected the taxi GPS data derived from didi taxi platform, and established the supply and demand matching model of taxi and passenger through the taxi reception and passenger demand, and studied a reasonable subsidy scheme to provide a reasonable basis for the taxi management department.

However, most scholars have studied the matching relationship between the supply and demand of passengers and taxis in urban areas in the Internet era, and few have studied the taxi configuration problems in airports. Therefore, this paper studies the problems of airport taxi, and provides a scientific decision-making basis for taxi drivers by establishing a model.

\section{Literature Review}

\subsection{Problem Overview}

- This paper analyzes the influencing mechanism of factors related to taxi 
driver's decision-making, comprehensively considers the changing law of airport passenger number and the income of taxi driver, establishes the decision-making model of taxi driver's choice, and gives the driver's choice strategy.

- Collect the relevant data of a domestic airport and its city taxi, give the choice scheme of taxi drivers in the airport, and analyze the rationality of the model and the dependence on relevant factors.

- In some cases, there are often taxi queuing and passenger queuing. There are two parallel lanes in the "load zone" of an airport. How should the management department set up the "load point" and reasonably arrange the taxi and passengers? Under the condition of ensuring the safety of vehicles and passengers, the total load efficiency is the highest.

- The taxi revenue of the airport is related to the mileage of passengers. The destination of passengers is far and near. Taxi drivers cannot choose passengers or refuse to take them, but they are allowed to take them back and forth for many times. The management department plans to give certain "priority" to some taxis carrying passengers back in short distance, so as to make the revenue of these taxis as balanced as possible, and try to give a feasible "priority" arrangement scheme.

\subsection{Taxi Resource Allocation}

Lu Weifeng et al. (2019) [5] studied the taxi resources allocation and subsidy scheme under the background of "Internet plus", and established the analytic hierarchy process model, and obtained the difference of matching degree of taxi resources supply and demand in different city and different time. Li Xiaochun (2019) [6] took Changsha City as the survey site, measured the matching degree of taxi supply and demand with the satisfaction rate of user demand, and found that although the existing subsidy scheme can alleviate the problem of taxi difficulty, the effect is not significant. Xu Rong et al. (2018) [7] established a rationalization index to analyze the rationalization degree of taxi transportation capacity scale, and then compared the matching degree of taxi resource supply and demand in different cities by using the fuzzy comprehensive evaluation method, and concluded that the taxi supply and demand degree in Beijing and Shanghai is higher.

\section{Model Building}

\subsection{Model Assumptions}

- Each passenger's ride is random and relatively independent.

- Each vehicle is relatively independent, and the taxi area is a system with limited capacity.

- There is no limit on the number of passengers.

- Do not consider the impact of special weather on passengers and taxi travel.

- There are two kinds of decision-making for taxi drivers: queuing or empty. 


\subsection{Symbol Description}

The symbols used in this model are described as follows, as shown in Table 1.

\subsection{Establishment of Model}

\subsubsection{Airport Taxi Status}

According to the taxi problems of national airports in recent years, it is found that the factors that affect taxi drivers' decision-making are as follows in Table 2.

First, if a taxi driver chooses to go to the airport storage area to wait for a pick-up, the waiting time depends on the number of taxis and passengers in line, which requires a certain time cost.

Second, if the taxi driver directly empty back to the city. Taxi drivers will pay no-load costs and may lose potential passenger income.

The following is the data of taxi demand and actual carrying capacity of each airport on a certain day. The list is as follows in Figure 1 and Figure 2.

Taking Beijing as an example, if the demand is $\mathrm{x}$ and the real load is $\mathrm{y}$, then the demand/real load can represent the time cost that taxi drivers need in the airport storage area, and establish a model.

Therefore, it can be concluded that when the number of passengers is small, the time cost is less. Taxi drivers choose to wait for a pick-up when the passenger volume is small, and return to the urban area directly when the passenger volume is large, which will obtain a large profit.

Table 1. Symbol description.

\begin{tabular}{cl}
\hline Symbol & Description \\
\hline$P$ & Taxi settlement price \\
$P^{0}$ & Taxi starting price \\
$\beta^{d}$ & Taxi mileage price \\
$L$ & Average taxi distance \\
$d_{0}$ & Taxi starting price mileage \\
$Q$ & Average travel demand of taxi passengers \\
$W$ & Average stay time, including waiting time and service time \\
$\lambda$ & $\begin{array}{l}\text { Average rate of customer arrival, i.e. average number of customers arriving in } \\
\text { unit time }\end{array}$ \\
\hline
\end{tabular}

Table 2. Taxi demand and actual load of each airport.

\begin{tabular}{|c|c|c|c|c|c|c|c|c|c|c|c|c|}
\hline \multirow{2}{*}{ Time } & \multicolumn{3}{|c|}{$1: 00$} & \multicolumn{3}{|c|}{$7: 00$} & \multicolumn{3}{|c|}{$13: 00$} & \multicolumn{3}{|c|}{$19: 00$} \\
\hline & Requirement & $\begin{array}{c}\text { Actual } \\
\text { load }\end{array}$ & $\begin{array}{l}\text { Actual load/ } \\
\text { Requirement }\end{array}$ & Requirement & $\begin{array}{c}\text { Actual } \\
\text { load }\end{array}$ & $\begin{array}{l}\text { Actual load/ } \\
\text { Requirement }\end{array}$ & Requirement & $\begin{array}{c}\text { Actual } \\
\text { load }\end{array}$ & $\begin{array}{l}\text { Actual load/ } \\
\text { Requirement }\end{array}$ & Requirement & $\begin{array}{c}\text { Actual } \\
\text { load }\end{array}$ & $\begin{array}{l}\text { Actual load/ } \\
\text { Requirement }\end{array}$ \\
\hline Beijing & 1243 & 393 & 0.316 & 570 & 254 & 0.446 & 634 & 213 & 0.336 & 938 & 330 & 0.352 \\
\hline Hangzhou & 411 & 285 & 0.693 & 226 & 160 & 0.708 & 551 & 363 & 0.659 & 1285 & 630 & 0.49 \\
\hline Wuhan & 90 & 70 & 0.778 & 78 & 68 & 0.872 & 85 & 58 & 0.682 & 111 & 91 & 0.82 \\
\hline
\end{tabular}




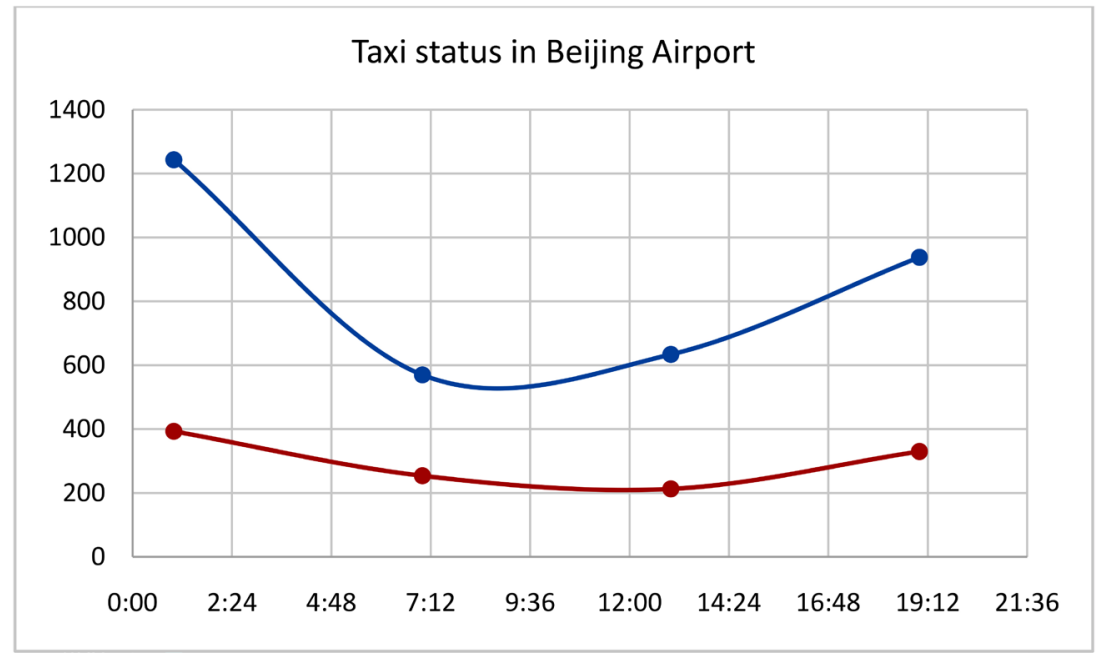

Figure 1. Taxi status in Beijing airport.

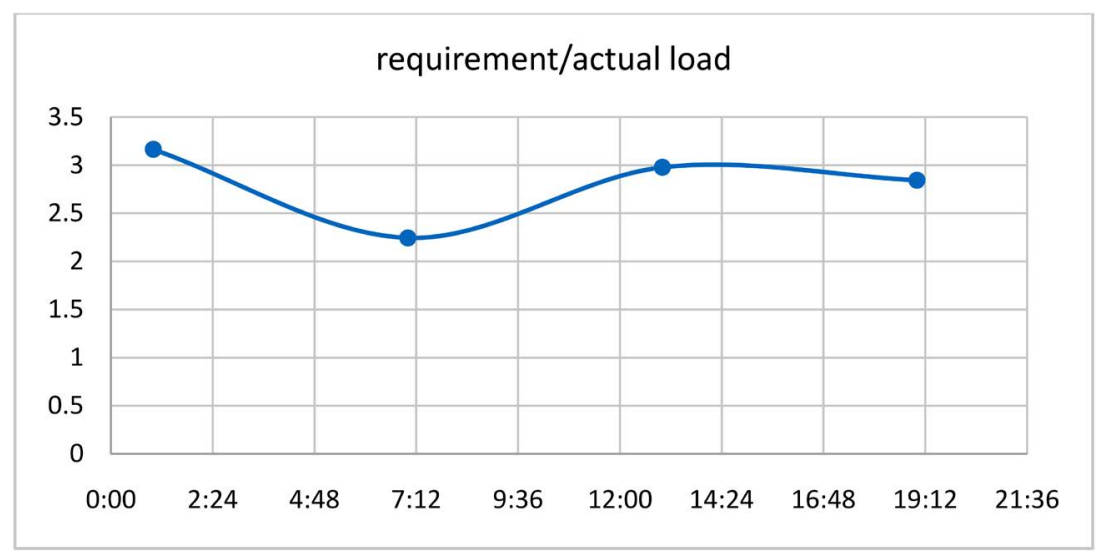

Figure 2. Taxi requirement/actual load of Beijing airport.

\subsubsection{Model Establishment}

Due to the no-load problem, the fuel will cause loss. According to the change of fuel oil price and the goal of maximizing profit, a taxi driver selection scheme based on reasonable profit level is developed.

Due to the nature of public transportation in taxi industry, taxi drivers can't make their own management strategies according to their own goals in the face of the change of fuel price. Taxi drivers will take the maximum profit as the goal and choose to pick up or empty at the airport according to the change of fuel price.

It is assumed by the model that the following conditions are true:

$$
\begin{gathered}
P=P^{0}+\beta^{d}\left(L-d_{0}\right) \\
Q=f(P, T, W) \\
R=P Q \\
C=c N=\left(c_{0}+\lambda v x\right) N \\
B=R-C=P-c N
\end{gathered}
$$




$$
T=\frac{L}{v}
$$

$P$ is the settlement price of taxi, $P^{0}$ is the starting price of taxi, $\beta^{d}$ is the mileage price of taxi, $L$ is the average driving distance of taxi, $d_{0}$ is the starting price mileage of taxi, $Q$ is the average travel demand of taxi passengers, $V$ is the average speed of taxi, $T$ is the travel time, $R$ is the money earned by taxi, $C$ is the cost required by taxi, and $B$ is the profit earned by taxi.

\section{Conclusions}

It can be seen from the model in this paper that in order to ensure the maximization of benefits, the decision made by taxi drivers depends not only on the demand of passengers, but also on the fuel consumed in the process of taxi driving. Therefore, this paper puts forward the following suggestions for taxi drivers on the allocation of airport taxi resources:

First, if the taxi driver's queuing time is short, because the queuing time is less than the empty time, and there is no fuel consumption in the queuing scheme, it is a more scientific decision to choose the airport taxi waiting area.

Second, if the taxi driver has been waiting for a long time to receive passengers, and the driver has received the passengers when he chose to empty, but the taxi who chose to queue has not received the passengers, the fuel consumption of the empty reception is less than the benefits of the reception. According to the model established in this paper, it is a reasonable decision to select the empty reception.

Third, if the taxi drivers queue for a long time to pick up passengers, and the drivers choose to empty before, they don't receive passengers, but choose to empty when they receive passengers, the fuel consumption of empty pick-up is greater than the benefits of pick-up. According to the model built in this paper, it is a more reasonable decision to choose queue to pick up passengers.

\section{Conflicts of Interest}

The author declares no conflicts of interest regarding the publication of this paper.

\section{References}

[1] Yi, C. (2018) Optimized Allocation of Taxi Resources Based on Logit Model. Journal of Yichun University, 40, 41-43+114.

[2] Hao, B., Chen, F. and Liu, Y. (2018) Based on AHP to Solve the "Internet Plus" Era of Taxi Resources Allocation. Finance Economy, No. 12, 108-110.

[3] Ma, S., Wang, H. and Zhang, F.H. (2018) Taxi Resources Allocation and Optimization Strategies in the Era of Internet Plus: Taking Lanzhou as an Example. Chinese and Foreign Entrepreneurs, No. 31, 197-198.

[4] Wang, M., Wan, Q., Zhu, P. and Xian, J. (2017) Taxi Resource Allocation Based on a New Supply-Demand Matching Model. Science and Technology Innovation and Application, No. 32, 25-26. 
[5] Lu, W., Wang, Q., Ma, L. and Han, X. (2019) City Taxi Resources Allocation in the Internet Plus Era-Application Case Study and Practice of Engineering Mathematics. Shandong Industrial Technology, No. 12, 240-241.

[6] Li, X. (2019) Taxi Resources Allocation in the Internet Plus Era. Modern Commercial and Trade Industry, 40, 85-86.

[7] Xu, R., Ceng, S. and Li, K. (2018) Analysis of the Matching of Supply and Demand of Taxi Resources in the Era of Internet Plus. Science and Education Guide, No. 8, 144-145+153. 